\title{
El tropero y el origen de la burguesía en el Cono Sur (Mendoza, siglo XVIII) ${ }^{1}$
}

PABLO LACOSTE*

Resumo: Este artigo aprofunda a análise sobre a carreta e o tropeiro, para definir em que medida contribuíram para o processo de construção de uma cultura empresarial na América Colonial, levando ao surgimento de uma burguesia. Atenta-se, em especial, para temas como mobilidade social, riscos empresariais, fomento do crédito em confiança ou por hipoteca de carretas, circulação de idéias e configuração de um ethos capitalista. Este trabalho constitui a continuação e a conclusão de um anterior intitulado "Carretas y transporte terrestre bioceánico: la ruta Buenos Aires-Mendoza en el siglo XVIII" (Estudos Ibero-Americanos, vol. XXXI, nำ 1, 2005).

\begin{abstract}
This paper deepens the study on the wagon and wagon drivers as socioeconomic actors. The aims of the present work is to determine their contribution to the process of building of an entrepreneurial culture in colonial America South Cone. It focuses on the wagon drivers' social mobility, entrepreneurial risks, credit networks, circulation of ideas, and the rise of a capitalistic ethos. This article is the conclusion of the previous paper "Wagon and Atlantic-Pacific terrestrial transportation: the Buenos Aires-Mendoza route, in $18^{\text {th }}$ century" (Estudos Ibero-Americanos, vol. XXXI, n. 1, 2005).
\end{abstract}

Palavras-chave: Carreta. Mobilidade social. Cultura empresarial.

Key words: Wagon. Social mobility. Entrepreneurial culture.

El presente artículo examina el aporte de los troperos o carreteros al surgimiento de la cultura empresaria y la burguesía en el Cono Sur. En este sentido cumplieron un papel parecido al que cupo en La Serena (Reino de Chile) a los hacendados, mineros y comerciantes, como ha estudiado Aranguiz, ${ }^{2}$ y a la tarea que reali-

1 Artículo elaborado en el marco del Proyecto "La viticultura en Cuyo y el Valle Central de Chile (1700-1850)", financiado por FONDECYT (Chile), no 1051109.

Universidad de Talca, Chile. E.mail: placoste@utalca.cl

2 Donoso, Horacio Aránguiz. Notas para el estudio de algunos hacendados, mineros y comerciantes serenenses. Siglos XVI al XIX. Boletín de la Academia Chilena de la Historia, $\mathrm{n}^{\circ}$ 103, 1993, p. 203-225.

Estudos Ibero-Americanos. PUCRS, v. XXXI, n. 2, p. 177-205, dezembro 2005 
zaron en Antioquia (Virreinato de Nueva Granda) los mineros, comerciantes y labradores de acuerdo a los trabajos de Ann Twinam. ${ }^{3}$ Pero en comparación con estos dos casos, la novedad de este trabajo se encuentra en el sector que se examina: los empresarios del transporte terrestre de tracción a sangre, es decir, las carretas.

A su vez, este tema es parte de un problema mayor, que tiene que ver con la construcción de un ethos capitalista en América Latina, una mentalidad conducente al surgimiento de una burguesía. En este plano, los troperos no actuaron solos. Otros actores sociales también contribuyeron a este proceso, como los arrieros, los viticultores y las viticultoras, los pulperos y pulperas. Ellos impulsaron actividades más complejas que la mera producción primaria, al avanzar en el plano de la industria, el transporte y el comercio. $Y$ de esta forma, contribuyeron a propiciar la puesta en marcha de una cultura empresaria y en cierta forma, las burguesías regionales. En otra parte nos hemos referido a los actores citados. ${ }^{4}$ En el presente artículo, nos centramos en los troperos y sus carretas.

El presente artículo es continuación de uno anterior, titulado "Carretas y transporte terrestre bioceánico: la ruta Buenos AiresMendoza en el siglo XVIII", publicado en Estudos IberoAmericanos, volumen XXXI, numero 1, 2005, paginas 7-34. En este nuevo trabajo se profundiza el problema de los troperos y sus carretas con vistas a profundizar su significado cultural, social y económico en la región.

\section{Troperos y movilidad social}

El oficio de los troperos se convirtió en un espacio eficaz de movilidad social. Resulta notable cómo, en relativamente poco tiempo, los carreteros lograban mejorar su posición económica, acumular capital y reunir bienes. Así se desprende de la lectura de los testamentos de troperos en los cuales se indica por un lado, los

3 Twinam, Ann. Mineros, comerciantes y labradores: las raíces del espíritu empresarial en Antioquia, 1763-1810. Medellín: FAES, 1985.

4 Lacoste, Pablo. La vitivinicultura en Chile Trasandino (Mendoza, 1561-1776). Colonial Latin American Historical Review 12, vol. 2, (spring 2003); Id. El arriero y el transporte terrestre en el Cono Sur (Mendoza, 1780-1800) (aceptado para publicación en Revista de Indias, volumen 65, $\mathrm{n}^{\mathrm{O}}$ 35, Madrid, 2005); Id. Vida y muerte de doña Melchora Lemos: empresaria vitivinícola y terciaria de la Orden de Predicadores, Mendoza, Reino de Chile, 1691-1741 (aceptado para publicación en Revista de Indias, volumen 66, Madrid, 2006). Id. Mujer y empresa: viticultoras y pulperas en Mendoza (1561-1852) (ponencia presentada en VI Congreso Argentino Chileno de Estudios Históricos, Universidad de La Serena, 27 al 29 de abril 2005). 
bienes que se entraron al matrimonio y luego, los que se poseían en el momento de testar. En varios casos se puso en evidencia que, en relativamente poco tiempo, se habían logrado mejoras sensibles.

Tres casos paradigmáticos de movilidad social fueron los de Melchor Videla, Mateo Delgado, troperos principales de la región. "Al contraer matrimonio - señaló Videla - traje a él seis carretas aperadas cuyo número de bueyes eran los necesarios para viajar". ${ }^{5}$ Luego recibió como herencia de sus padres una cantidad de bienes no definida. Pero su flota de carretas subió bruscamente; llegó a fletar partidas de 38 carretas, y terminó por convertirse en el mayor tropero de la región. Por su parte, la historia de la movilidad social de Mateo Delgado la conocemos a través de sus propias palabras:

Cuando contraje matrimonio tenía por bienes míos propios seis carretas con algunos bueyes, de seis a siete por cada una. Don Francisco Basualdo mi suegro, después de casado, para hacer viaje para esta ciudad, me avió con 8 carretas y 100 bueyes, con cargo que le pagase en esta ciudad a don Santiago Puebla $\$ 100$ y a don Ambrosio Vargas otros $\$ 100$, lo que efectué. Verificados estos pagos me aproveché de dichas carretas y bueyes con cuya ayuda y mi costo principal he reunido lo que hoy poseo. ${ }^{6}$

A partir de su propio esfuerzo y trabajo personal, don Mateo logró consolidarse dentro del gremio de los carreteros. Dentro de las jerarquías que hemos usado en el presente texto, Delgado actuó como tropero principal. Fue el segundo empresario del rubro más importante de la región, después de don Melchor Videla. Servía la ruta de Buenos Aires a Mendoza con tropas de hasta 34 carretas, según los registros de la Aduana. La evolución de su patrimonio fue muy interesante; al casarse, aportó al matrimonio bienes por valor de \$1.000, en tanto su mujer "no trajo cosa alguna". ${ }^{7}$ Con su trabajo logró acumular un capital que fue, a su vez, redistribuyendo entre sus hijos; "cuando se casó mi hija, doña María del Carmen, le dí el dote de \$1.000”. Además “a mi hijo don Juan Francisco le tengo dado a cuenta de su legítima (herencia), 14 carretas y un carretón con 150 bueyes escogidos, 12 mulas mansas y $\$ 300$ en plata”. También compró propiedades raíces, como la estancia que

5 Testamento de Melchor Videla, Mendoza, 8 de julio de 1810. AHM, Protocolo de Escribanos n ${ }^{\circ} 162$ fols 58 v. -59 .

6 Testamento de Mateo Delgado, Mendoza, 30 de junio de 1782. AHM, Protocolo de Escribanos no 112 fols 65 .

7 Testamento de Mateo Delgado, Mendoza, 19 de julio de 1798. AHM, Protocolo de Escribanos no 136 , fols. 147 v. 
adquirió a Norberto Guevara. La prosperidad de sus negocios le permitió realizar una acumulación de capital que luego se tradujo en una notable capacidad de operar como agente financiero, tal como se examinará más adelante.

Otros dos grandes empresarios del rubro, como Agustín Videla y Tomás Carrasco, experimentaron un proceso similar. "Cuando contraje matrimonio - señaló Videla - traje a él nueve carretas aviadas". Con el tiempo logró crear una empresa floreciente. Su flota llegó a poseer 37 carretas que "están bien aviadas, de todos los utensilios necesarios para ellas". Además, Videla poseía viñedos, campos con alfalfares y ganado mayor, incluyendo bueyes, mulas y caballos. Poseía también "12 esclavos hombres y mujeres, entre chicos y grandes". ${ }^{8}$ Más notable puede ser el caso de Carrasco; al casarse, ni él ni su mujer poseían bienes: "no trajimos cosa alguna al matrimonio, por lo que todo cuanto hay y hoy tenemos y poseemos, son gananciales”. Ello incluía:

El sitio en que vivo con lo edificado y plantado; cuatro alfalfares chicos; tropa de 12 carretas con 300 bueyes; las mulas y caballos que sirven a la tropa; un carretón usado y otro viejo; todo el ganado que se encuentra en la estancia de Melingüe a cargo de Colman, lo que se encontrare en la esquina y pulpería que está a cargo de Feliciano Núñez. ${ }^{9}$

El caso de Tomás Carrasco es muy relevante porque con su trabajo, no sólo acumuló un relevante capital, sino que se erigió en uno de los troperos principales de la región. Por su parte, don Antonio Lemos sostuvo que "traje al matrimonio dos alfalfares y una huerta de higueras; y mi mujer trajo una hijuela y una esclava". ${ }^{10}$ Luego se dedicó a los fletes y llegó a figurar en la categoría de troperos muy frecuentes, con partidas de hasta 15 carretas.

Los troperos Pascual Álvarez, Justo Alvarado también muestran con claridad este fenómeno de movilidad social. Álvarez comenzó sin capital alguno y, en relativamente poco tiempo, con su trabajo, logró constituir una posición relevante. En el gremio del flete, don Pascual Álvarez figuraba entre los troperos frecuentes; se especializó en la ruta de Buenos Aires a Mendoza, pero podía realizar servicios también entre éste y San Nicolás de los Arroyos;

8 Testamento de Agustín Videla, 15 de noviembre de 1800. AHM, Protocolo de Escribanos no 139 fols 114 .

9 Testamento de Tomás Carrasco, Mendoza, 4 de marzo de 1800. AHM, Protocolo de Escribanos no 139 fols 31-32.

10 Testamento de Antonio Lemos, Mendoza, 24 de abril de 1810. AHM, Protocolo de Escribanos no 162 fols. 40 . 
sus partidas llevaba entre 14 y 23 carretas. En su testamento, don Pascual afirma que "cuando contraje matrimonio no entré en él bienes ningunos ni la dicha mi mujer tampoco. Todos los bienes que hoy poseemos son habidos durante dicho matrimonio". ${ }^{11} \mathrm{Al}$ cabo de su vida, sus propiedades incluían "una tropa de 20 carretas aperadas con 300 y tantos bueyes, 30 mulas mansas, poco más o menos, una parte de estancia que compré en El Carrizal, y en ella 150 cabezas de ganado siendo 60 y tantas de ganado menor, 40 y tantas de ganado mayor y 80 y tantos caballos". Además tenía " 140 vacas en invernada, siete cuadras de tierra en alfalfares y otras junto a lo de Figueredo con alfalfares y una casita"; además poseía dos viñas y otras dos carretas que había cedido a una hija. La historia de don Justo Alvarado exhibe muchos aspectos parecidos. En el momento de casarse, ingresó al matrimonio "diez varas de terreno en el sitio de mi morada, en la traza de esta ciudad, y en las acequias de Gómez, \$54 en un sitio que se me debía por legítima herencia paterna, pues todo el resto de su valor lo pagué con los gananciales". ${ }^{12}$ Con su trabajo logró armar una sólida posición económica. Dentro de este oficio, Alvarado actuó como tropero frecuente en la ruta de Buenos Aires a Mendoza. Llegó a tener tierras cultivadas con alfalfa y una flota de más de 30 carretas.

La movilidad ascendente se nota también en el caso de Eusebio Rodríguez. Al casarse "no trajo mi mujer bienes algunos y yo traje una carreta con sus correspondientes bueyes". Luego, tras la muerte de sus suegros, recibieron algunos bienes más. Pero la base del crecimiento fue su trabajo personal. Llegó a poseer varias propiedades, incluyendo seis viviendas. ${ }^{13}$ En el oficio del transporte, don Eusebio Rodríguez estaba en la categoría de troperos principales y se dedicaba exclusivamente a servir la ruta Mendoza-Buenos Aires; sus caravanas eran de hasta 26 carretas. La trayectoria de Francisco Coria es otro buen ejemplo de la movilidad social ascendente de los troperos. Natural de Santiago de Chile, don Francisco se avecindó en Mendoza, donde contrajo enlace con Isabel Quiroga, nacida en esta ciudad. En el momento del matrimonio "no entré bienes algunos y mi mujer trajo el sitio y casa en que vivimos". Durante su vida de trabajo, Coria se desempeñó como carretero en la categoría de tropero poco frecuente, con viajes de Mendoza

11 Testamento de Pascual Álvarez, Mendoza, 2 de octubre de 1791. AHM, Protocolo de Escribanos no 126 fols 61 .

12 Testamento de Justo Alvarado, Mendoza, 6 de octubre de 1797. AHM, Protocolo de Escribanos nำ 133 fols. $137 \mathrm{v}$.

13 Testamento de Eusebio Rodríguez, Mendoza, 10 de noviembre de 1788. AHM, Protocolo de Escribanos no ${ }^{\circ}$ 120, fols. $82 \mathrm{v}$. 
hacia Buenos Aires y Santa Fe. Como resultado logró mejorar su posición expectante. Al redactar su testamento declaró que tenía, junto con los bienes originales, "el demás terreno que se encuentra en el sitio, parral de moscatel y todos los demás árboles y plantas que son habidos durante el matrimonio". Incluso "compré a Temporalidades 20 cuadras de tierra a censo redimible en $\$ 470 " .{ }^{14}$ Este fenómeno ascendente lo experimentaron no sólo los troperos principales, sino también los más modestos. Pedro Martínez también muestra la capacidad de movilidad social de este grupo. Martínez llevó al matrimonio "\$500 y mi mujer no trajo bienes ningunos". Con el trabajo personal, llegó a operar como tropero entre Mendoza y Buenos Aires, fletando caravanas de hasta 12 carretas. Logró mejorar el patrimonio familiar, el cual llegó a contar con "el sitio en que tengo edificada la casa de mi morada" y además un viñedo en el Alto Godoy, entre otros bienes. ${ }^{15}$

Los casos mencionados alcanzan como ejemplos de un sistema que operaba con bastante eficacia. El oficio de tropero fue un canal de ascenso y movilidad social de singular importancia en la época colonial. Muchas familias se iniciaron casi sin bienes, o con recursos muy modestos, y al cabo de una vida de trabajo duro al frente de las tropas de carretas, en viajes fatigosos a través de las pampas, lograron una acumulación de capital de distintas dimensiones, pero sin duda, capaz de exhibir una evolución clara del patrimonio, de menos a más.

El transporte carretero tenía una doble función desde el punto de vista de la movilidad social. Para los criollos era un mecanismo útil para ascenso y enriquecimiento. Pero ello se lograba con la consolidación del proceso de explotación de otras capas sociales, fundamentalmente la situación de los esclavos de origen africano, que eran parte importante de la rentabilidad que se generaba a través del transporte carretero. En este sentido, el sufrimiento humano de los esclavos era parte importante de la prosperidad de los hispanocriollos del Cono Sur.

\section{Troperos, viajes y riesgo empresario}

El viaje de las tropas de carretas a través de las pampas planteaba dificultades de diferentes tipos. Para llegar de Mendoza a

14 Testamento de Francisco Coria, Mendoza, 29 de octubre de 1802. AHM, Protocolo de Escribanos nํㅜ 145 fols $135 \mathrm{v}$.

15 Testamento de Pedro Martínez, Mendoza, 29 de agosto de 1780. AHM, Protocolo de Escribanos n⿳o 108 fols 57 . 
Buenos Aires, las carretas debían recorrer más de 200 leguas, atravesar ocho ríos y superar largos trechos sin agua. Debían llevar provisiones, incluyendo agua para beber. A los problemas naturales hay que añadir los culturales: con frecuencia las caravanas eran asaltadas por malones indígenas; además, estaban las dificultades para disciplinar a los peones, especialmente en el plano del consumo de alcohol.

El fuerte de Río IV tenía como misión garantizar la seguridad de la población de Córdoba, y de los troperos y arrieros que recorrían el camino entre Mendoza y Buenos Aires. Río IV se convirtió, poco a poco, en un lugar de gran animación, por la presencia permanente de los viajeros y sus carretas que llegaban a este punto a reponer fuerzas, encontrarse en una pulpería, hablar de negocios y practicar la entrañable amistad de los viejos amigos. Pero Río IV se convirtió también en lugar de conflicto cuanto, en 1740 el gobernador de Córdoba del Tucumán resolvió gravar el aguardiente en tránsito con un impuesto especial. Se obligó a los troperos a detenerse, destapar sus botijas para verificar si llevaban vino o aguardiente, y pagar el tributo de $\$ 6$ por botija (posteriormente, a mediados de 1741, fue reducido a la mitad). Esta decisión causó un gran impacto en la industria pues anualmente Cuyo remitía 8.000 botijas de aguardiente a Buenos Aires. Además, la tasa impositiva era altísima, pues significaba casi el $50 \%$ del valor del producto: tanto en Mendoza como en San Juan el valor comercial de la botija oscilaba entre $\$ 11$ y $\$ 11$ con 4 reales.

Las tropas de carretas tuvieron que acatar estas disposiciones, lo cual generó una serie de consecuencias inesperadas. En primer lugar, los empresarios vitivinícolas debieron entregar dinero en efectivo a los troperos para que lo llevaran en el viaje y pagaran el impuesto. En estas circunstancias, se produjo una conflictiva situación con el manejo del dinero que muchas veces era robado. Un informe del Cabildo de Mendoza aseveró que "los guardias les quitan el dinero y las botijas de aguardiente". No conformes con esto, los guardias llegaron a despojar a los troperos de otros bienes. Así por ejemplo "a don Pedro Sánchez le quitaron los platos de plata, cucharas, mate, pie y bombilla, ponchos, frenos y avíos, y lo mismo a don Domingo Morales". ${ }^{16}$ Hubo también casos de cohecho o soborno: los guardas de Río IV obligaban a los troperos a realizar pagos ilegales para incentivarlos a no usar de la fuerza para entorpecerles el viaje. Según un documento elaborado por el

16 Poder dado a Arizmendi para realizar gestiones ante el Virrey del Perú, Mendoza, 27 de febrero de 1745. AN, Capitanía General, volumen 800, fols 219. 
Cabildo de Mendoza, con frecuencia, "se ve precisado el dueño a darle algo más de lo que le quitaron para que lo dejen pasar". ${ }^{17}$ Los guardias sobornaban a los troperos para permitirles transitar hacia Buenos Aires.

Al destapar las botijas en medio del camino se generó un serio problema técnico. Los viticultores cuyanos habían logrado un importante avance en sus métodos de envasado y conservación de sus vinos y aguardientes para llegar a los puntos de venta con una calidad razonable. Pero estos procedimientos, con el tapado de la botija con yeso y otros materiales, se hacían en las instalaciones de las bodegas. Era muy difícil repetir la operación en medio de las pampas. Por lo tanto, ante el registro que efectuaba la aduana de Río IV, las botijas debían continuar viaje de allí a Buenos Aires en malas condiciones. Los documentos de la época han explicado el problema en los siguientes términos:

para reconocer las dichas guardias de Río IV si son botijas de vino o aguardiente, las abren, y como nunca pueden taparse con la seguridad que se hace en Mendoza, porque van ya de camino en la carretería, se vierte muchísimo caldo, con lo que se ladea o zangolotea la botija en las caminatas, demás del mucho que hurta la peonada en el discurso del camino. ${ }^{18}$

Al romperse el tapado original de las botijas, se generaban tres problemas: se deterioraba el vino en el largo viaje hacia Buenos Aires; se derramaba parte del caldo por el movimiento de las carretas; y se generaba una situación tensa con los peones, que se veían tentados con la posibilidad de beber los vinos y aguardientes. Otro documento insiste con estos temas: "se vierte muchísimo aguardiente, además del que votan los peones de la carretería con canutos, o del modo que pueden por causa de dicha apertura". Por tal motivo "llega a Buenos Aires la botija muy mermada". ${ }^{19}$ Para simular el hurto, los peones optaban por agregarle agua, lo cual deterioraba aún más la calidad del producto. Otro documento explica el fenómeno en los siguientes términos:

como (las botijas) quedan mal tapadas, con el sangoloteo de la carreta, se vierten, además del mucho caldo que hurtan los peones en la distancia del camino que media de Río IV a Buenos Aires, a más que

17 Poder dado a Arizmendi para realizar gestiones ante el Virrey del Perú, Mendoza, 27 de febrero de 1745. AN, Capitanía General, volumen 800, fols 211.

18 Poder dado a Arizmendi para realizar gestiones ante el Virrey del Perú, Mendoza, 27 de febrero de 1745. AN, Capitanía General, volumen 800, fols 200.

19 Poder dado a Arizmendi para realizar gestiones ante el Virrey del Perú, Mendoza, 27 de febrero de 1745. AN, Capitanía General, volumen 800, fols 204 v. 
por que se llene la botija, los peones le echan agua y se echa a perder todo el vino o aguardiente. ${ }^{20}$

Los viticultores cuyanos se vieron seriamente afectados por el destape de las botijas y el cobro de los impuestos. Sintieron que la industria de la vid y el vino estaba amenazada y pusieron en marcha un plan para obtener la derogación de la medida. Sobre todo porque este tributo se sumaba a una abultada carga impositiva que aplicaba la Corona a una producción que no tenía ningún interés en fomentar, pues le hacía competencia a una de las pocas industrias que tenían los españoles. En estas circunstancias, muchos empresarios cuyanos consideraron que debían luchar con todos sus medios contra este impuesto. Para avanzar en esta dirección, los Cabildos de Mendoza y San Juan enviaron al viticultor don Miguel de Arizmendi como Procurador a la ciudad de Lima, para que lograra del virrey del Perú, la supresión de este impuesto. Tal como se ha estudiado en otra parte, el viaje de Arizmendi a Perú se vio coronado con éxito. ${ }^{21}$ Pero la derogación del impuesto de Río IV demandó varios años. Mientras tanto, el problema seguía pendiente y los empresarios cuyanos buscando la forma de eludirlo. Por ello trataron de atravesar las pampas al sur del fuerte de Río IV, para evitar los controles. Pero entraron así a territorio indígena, y las consecuencias fueron todavía más traumáticas. En efecto,

los carreteros, huyendo de esta cobranza abrieron nuevo camino por el despoblado y los guardias de Río IV los persiguieron. Algunas tropas de mulas, cargadas de aguardiente, para huir de la cobranza del impuesto, las han perseguido y a los arrieros, comisándolos, los guardias de Río IV, y los han llevado a la ciudad de Córdoba, donde han experimentado el perjuicio de perder su hacienda. ${ }^{22}$

Los guardias encargados del cobro del impuesto no sólo controlaban el camino de Río IV, sino un amplio radio de acción alrededor de este punto. Ellos patrullaban la zona para atrapar a los troperos que trataban de eludir el control, el destape de las botijas y el pago del impuesto. Y los problemas que se generaban eran muy costosos: el tropero era arrestado, conducido por la fuerza a Córdoba, castigado y afectado en sus bienes y compromisos comerciales. Frente a esta amenaza, los troperos buscaron alternati-

20 Poder dado a Arizmendi para realizar gestiones ante el Virrey del Perú, Mendoza, 27 de febrero de 1745. AN, Capitanía General, volumen 800, fols 208-209.

21 Acevedo, Edberto Oscar. Los impuestos al comercio cuyano en el siglo XVIII. Revista Chilena de Historia y Geografía, 126, 1958, p. 58-69.

22 Poder dado a Arizmendi para realizar gestiones ante el Virrey del Perú, Mendoza, 27 de febrero de 1745. AN, Capitanía General, volumen 800, fols 215. 
vas cada vez más audaces y llegaron a internarse en las pampas, fuera del control real y efectivo de los hispanocriollos. Mientras más al sur de Río IV se realizara la travesía, menos riesgo tenían de caer en manos de los guardias, pero paralelamente aumentaba otro peligro: el malón indígena.

La muerte del tropero Hermenegildo Quiroga fue el resultado de este intento de los carreteros por eludir la guardia de Río IV y sus impuestos. Don Hermenegildo debía viajar de Cuyo a Buenos Aires con 50 cargas, 200 mulas y 10 personas. En lugar de seguir por la ruta tradicional, se internó por las pampas abiertas, al sur del fuerte del Río IV. Grande fue su sorpresa al encontrarse, inesperadamente, rodeado por un malón indígena, ante el cual se hallaba indefenso. Los hechos fueron narrados por don Vicente Delgado, vecino natural de la ciudad de San Juan, el cual señaló que don Hermenegildo

fue por el despoblado, dio en manos del enemigo y perdió la vida con sus peones; más de siete mataron los indios bárbaros y se llevaron todas las mulas, los arreos y cargas; solo tres quedaron vivos. ${ }^{23}$

La muerte de don Hermenegildo Quiroga y siete de sus peones no fue un hecho excepcional. Era parte del riesgo que corrían los troperos y arrieros en la realización de su oficio. Hubo otros casos de heridos y muertos, en estos desolados caminos. Entre ellos podemos mencionar los que se suscitaron en torno a las pulperías del Desaguadero, en 1805. Las pulperías aisladas de la campaña, podían convertirse en espacio de alta conflictividad para las tropas de carretas. Sobre todo si los peones se entregaban al consumo de alcohol, se embriagaban y perdían luego todo sentido de la responsabilidad con las tareas y obligaciones asumidas antes de iniciar el viaje. En este aspecto, los sucesos de las pulperías del río Desaguadero, muestran un ejemplo interesante.

Las pulperías de Desaguadero surgieron a fines del siglo XVIII, 40 leguas al este de la ciudad de Mendoza, en la ruta entre ésta y Buenos Aires. El permanente flujo de carretas aseguró una clientela importante, y el negocio prosperó. Una tras otra, se abrieron varias pulperías en este sector. El lugar elegido era muy adecuado para estos fines: era una parada casi obligatoria pues allí se debía preparar el vado del río. Y cuando llegaba mucho caudal de agua, podía ser preciso descargar las carretas para facilitar el cru-

23 Declaración de Vicente Delgado, natural de San Juan. En: Poder dado a Arizmendi para realizar gestiones ante el Virrey del Perú, Mendoza, 27 de febrero de 1745. AN, Capitanía General, volumen 800, fol. 215. 
ce; luego era necesario volver a cargarlas, con lo cual, el trabajo era pesado e intenso. O bien, se podía aguardar unos días, hasta que el agua descendiera, y cruzar más fácilmente el río. En resumidas cuentas, sea para aguardar el momento oportuno, o para reparar fuerzas, la zona de Desaguadero era muy adecuada para levantar allí un polo se servicios, abastecimiento y proveeduría para los troperos y carreteros.

Los peones llegaban a este lugar después de cuatro días de cansador viaje desde la capital cuyana. Y con gran ansiedad ingresaban a las pulperías para reparar fuerzas, alimentarse y gozar de un encuentro con amigos que llegaban de otras regiones. El vino circulaba con generosidad y algunos se emborrachaban. En estas condiciones, a veces los patrones y capataces tenían problemas para lograr que retomaran sus tareas, sobre todo en la delicada misión de cruzar el Desaguadero en balsas. No faltaron peones que se resistieron a sus capataces, y estallaron los conflictos. Hubo malos tratos, golpes, heridos y hasta muertos en los incidentes del 14 de abril de 1805. Un mes más tarde, el caso ingresó a la Justicia. Un grupo de siete troperos, entre patrones y capataces, se presentó ante las autoridades para denunciar los hechos y solicitar la clausura inmediata de todas las pulperías de Desaguadero. Estas fueron calificadas en términos de

escoria, tropiezo y mal de todas las tropas del Reino, pues, acostumbrados ya los peones a parar en ellas y haciendo uso de las bebidas que se les franquea, no sólo faltan a todo el trabajo, se quedan y abandonan las tropas y boyadas, sino que también defectúan de las balseadas donde hacen peligrar la carga, siendo imponderables los estrechos en que nos vemos los amos y capataces sin poder hacer caminar las tropas, sacar de aquellas pulperías a los peones, ni contener sus peleas y averías que han repetido con eso, sin que en tan riesgosas circunstancias puedan los amos valerse, en aquellos desamparos, de arbitrio alguno ni libertar sus tropas y cargamentos que transitan expuestos por la embriaguez de las peonadas. ${ }^{24}$

El documento de los troperos expresaba la acción de las pulperías en el sentido de romper las pautas de disciplina laboral entre los peones. Además del problema laboral, se produjo también una situación de rebelión general de los peones contra sus capataces y patrones, hasta llegar al derramamiento de sangre. El documento señala al respecto que era:

24 Solicitud de cierre de pulperías en Desaguadero, Mendoza, 10 de mayo de 1805. AHM, Época Colonial, Judicial Civil, Letra P, Carpeta 177 documento 14. 
notorio que asesinaron hace poco a don Joaquín Moyano sus propios peones; que caminaron enojados con el peón que los obligó a salir de las expresadas pulperías en las que mataron el 14 de abril a un mozo, los peones de don Manuel Peralta, habiendo estropeado malamente al hijo de don Miguel Salomón que iba con su tropa de carretas sin que sea posible remediar los males que en general a todos causan aquellas pulperías y las embriagueces en ella de todas las peonadas en las tropas. ${ }^{25}$

Los peones, alegres y borrachos en las pulperías, no estaban en condiciones de acatar las órdenes de sus mandantes. Se rebelaron, mataron a un peón y a un empresario, a la vez que golpearon al hijo de otro "notable" del ramo de tropas de carretas. Lejos de la fuerza pública y de la autoridad oficial, en medio del desierto y desinhibidos por el alcohol, los peones se revelaron en forma clara y franca contra sus patrones. Este tipo de conflictos eran recurrentes dentro del gremio. Los troperos afectados por estos hechos eran empresarios conocidos en el medio. Don Miguel Salomón figuraba en los registros de Aduana desde 1797, prestando servicios en la ruta entre Mendoza y Buenos Aires. Por su parte, don Manuel Peralta era uno de los mayores troperos de la región. Llevaba cerca de un cuarto de siglo en este oficio. Su principal trabajo se encontraba entre Mendoza y Buenos Aires; pero servía también las rutas entre la capital cuyana y otras ciudades, como Córdoba y Santa Fe. En los nueve años que fueron registrados por la aduana entre 1782 y 1799, don Manuel realizó 42 viajes con 633 carretas. Era uno de los cuatro troperos más importantes de Mendoza. A pesar de todo se encontró ante esta difícil y conflictiva situación.

Las pulperías aisladas de la campaña, la prepotencia de los guardias y fortineros, la irrupción del malón indígena y los conflictos con los peones eran parte de las dificultades que debían afrontar los troperos para llevar adelante su oficio, mantener el servicio del transporte y garantizar el sistema regular de cargas entre Mendoza y Buenos Aires. A pesar de los obstáculos, el servicio de los troperos se abrió camino y logró asegurar el abastecimiento y el acceso a los mercados.

25 Solicitud de cierre de pulperías en Desaguadero, Mendoza, 10 de mayo de 1805. Documento firmado por los troperos Bernardino Morales, Manuel Peralta, José Obredor, Sebastián Baldor de la Portilla, Santiago José Puebla, Esteban Rodríguez y, a ruego de don Francisco Silva, José Serrano. AHM, Época Colonial, Judicial Civil, Letra P, Carpeta 177 documento 14 . 


\section{Las carretas como bienes de préstamo, hipoteca y herencia}

La importancia que alcanzó la carreta en la economía regional, hizo de la misma un objeto de singular valor, muy presente en la mediación de las relaciones sociales. Las carretas, sus bueyes y avíos, se compraban, vendían, prestaban, hipotecaban y heredaban. Es notable el papel que tuvieron en la economía de la colonia. En muchos casos valían más que la tierra: como en Mendoza sólo tiene valor la tierra con riego, y apenas se logró irrigar una pequeña parte de la superficie, los bienes que se negociaban estaban más orientados a los aspectos dinámicos de la economía que la tradicional tendencia latinoamericana a centrar la riqueza en la posesión de la tierra.

El valor de una carreta con sus cuatro yuntas bueyes oscilaba entre $\$ 70$ y $\$ 170$. Así por ejemplo, don Pascual Álvarez cedió a su hija Rosalía "dos carretas en $\$ 100$ las dos, con 16 bueyes apreciados a \$5 cada uno". Por lo tanto cada carreta con sus ocho bueyes costaría \$90. Por su parte, Alejo Aldunate transmitió a su hijo Roberto Adulante "dos carretas y 16 bueyes; las carretas a $\$ 60$ y los bueyes a $\$ 6 " .{ }^{26}$ En este caso, cada carreta con sus ocho yuntas de bueyes se cotizaba a $\$ 108$. Había también opciones más modestas y más ambiciosas. Mariano de la Concha vendió a Manuel Videla seis bueyes en $\$ 60$, es decir, a $\$ 10$ cada uno. ${ }^{27}$ Don Nicolás Corvalán compró al tucumano Juan Laguna "dos carretas a $\$ 90$ cada una y 32 bueyes a $\$ 6 " .{ }^{28}$ Antonio Frutos entregó a su hija Juana "dos carretas que podrían valer, entre una y otra, $\$ 60 " .{ }^{29}$ En resumidas cuentas, la carreta oscilaba entre $\$ 30$ y $\$ 90$, en tanto los bueyes costaban de $\$ 5$ a $\$ 10$.

La carreta se distinguía por su rentabilidad. Porque el costo de la carreta y su boyada era prácticamente igual al valor del flete de un viaje entre Mendoza y Buenos Aires el cual, como hemos visto, rondaba entre $\$ 80$ y $\$ 125$. La prestación de este servicio tenía también otros costos, sobre todo el jornal de la peonada, que normalmente ascendía a $\$ 1$ diario. Pero si un grupo de hermanos y cuñados realizaba el viaje como empresa familiar, era posible, con

26 Testamento de Alejo Aldunate, Mendoza, 13 de octubre de 1797. AHM, Protocolo de Escribanos n ${ }^{\circ} 133$ fols. 154

27 Testamento de Mariano de la Concha, Mendoza, 30 de julio de 1794. AHM, Protocolo de Escribanos no 130 fols 112 .

28 Testamento de Nicolás Corvalán, Mendoza, 3 de julio de 1800. AHM, Protocolo de Escribanos no 140 fols fols. 57 .

29 Testamento de Antonio Frutos, Mendoza, 21 de abril de 1788. AHM, Protocolo de Escribanos no 120 , fols $29 \mathrm{v}$. 
el trabajo personal y partiendo de un pequeño capital, poner en marcha una empresa. Además, la industria de Mendoza generaba la necesidad de colocar el excedente en los mercados de Buenos Aires, sobre todo cuando se acercaba el tiempo de vendimia y había que liberar las tinajas de las bodegas para el vino nuevo. Por lo tanto, la demanda de carretas era constante. Como resultado, la carreta era un bien altamente cotizado y podía realizarse con toda facilidad, ya por venta, ya por prestación de servicios de flete.

La carreta podía ser muy apreciada como donación para manifestar agradecimiento y afecto dentro de la familia. En 1772 doña Josefa Morales resolvió donar una carreta con 12 bueyes y demás aperos al niño Juan Francisco Guevara, a quien ella había criado. El obsequio se realizó "por cuanto se halla obligada a corresponder los muchos servicios que le ha hecho". 30

Los bueyes, carretas y avíos eran bienes tan sensibles que, en caso de préstamos, se labraba un acta formal para asegurar la devolución. Así lo hicieron dos conocidos troperos, Esteban Rodríguez y Juan Gregorio Santander. Solicitaron prestados 30 bueyes a don Fernando Guiraldes para viajar a Buenos Aires, y protocolizaron un acta para hacer fehaciente el compromiso de la devolución después de la travesía. ${ }^{31}$ El mismo día, Esteban Rodríguez con otro compañero (Pablo Vidal) solicitaron al mismo Guiraldes otros 15 bueyes para completar las tropas. También en este caso se protocolizó el acta correspondiente. ${ }^{32}$

Carretas y bueyes ocupaban, junto con las viñas, un lugar muy especial en los testamentos. Sobre todo porque constituían la base económica de la segunda actividad más rentable de la producción de bienes y servicios de Mendoza. Los documentos de la época lo muestran con frecuencia. En 1769 doña María Jiménez declaró como sus bienes "media cuadra de sitio en la que actualmente vive y una carreta". ${ }^{33}$ En 1773 redactó su testamento el tucumano Santiago Rojas, y declaró por sus bienes "tres carretas con todos sus aperos, seis caballos, una mula redomona, un buey y dos

30 Acta de donación de Josefa Morales, Mendoza, 31 de octubre de 1772. Protocolo de Escribano José Lagos (Mendoza: UNC, 1968), p. 45.

31 Préstamo a Esteban Rodríguez y Juan Gregorio Santander, Mendoza, 9 de setiembre de 1788. Protocolo de Escribano José Lagos (Mendoza: UNC, 1968), p. 123.

32 Préstamo a Esteban Rodríguez y Pablo Vidal, Mendoza, 9 de setiembre de 1788. Protocolo de Escribano José Lagos (Mendoza: UNC, 1968), p. 123.

33 Testamento de María Jiménez, Mendoza, 16 de setiembre de 1769. Protocolo de Escribano José Lagos (Mendoza: UNC, 1968), p. 141. 
solares" ${ }^{34}$ La presencia de la carreta entre los bienes testamentarios fue una constante.

La carreta también servía para obtener créditos hipotecarios. En la época colonial existían dos modalidades de empeño de un bien para dar seguridad a un préstamo: la hipoteca y la prenda. Ambas tenían en común la capacidad de ofrecer una garantía real para la obtención de un crédito; pero tenían también sus diferencias; la prenda consistía en un bien mueble que se entregaba al acreedor; en cambio la hipoteca se realizaba sobre un bien inmueble o propiedad raíz, cuya tenencia permanecía en manos del propietario. ${ }^{35}$ Dentro de este esquema, el alto valor que se otorgaba a la carreta hizo de ella un caso excepcional por el cual se podía establecer un crédito hipotecario sobre la garantía de un bien mueble. Así por ejemplo, en 1772, don Manuel Martínez Caballero y doña Bárbara León elaboraron un documento por el cual se obligaban a pagar \$701 a don Manuel de Abarrategui, por la entrega de géneros de Castilla. Los firmantes se comprometían a pagar en mayo del año siguiente "obligando don Manuel las carretas de bueyes y la carga que en ellas conduce y doña Bárbara hipoteca su casa y sitio en que vive". ${ }^{36}$ Una acción parecida realizó don Juan Manuel Sierra, tropero con varios viajes entre Mendoza y Buenos Aires. Al necesitar dinero, solicitó un préstamo y en garantía, elaboró un documento en el cual "se obliga a pagar a don Javier Zuloaga, en el término de un año, la cantidad de $\$ 225$, obligando su persona y bienes, y en especial hipoteca 12 carretas y 150 bueyes". 37 Asimismo, en 1787 don Francisco Gallardo se obligó a pagar \$454 a don Francisco Segura, y como garantía real de la operación, puso "las carretas, bueyes y demás ganado y sitio que posee, los que hipoteca". 38 Este sistema permitía la compra de carretas con un crédito hipotecario: quedaban las mismas carretas en garantía. En efecto,

34 Testamento de Santiago Rojas, Mendoza, 25 de octubre de 1773. Protocolo de Escribano José Lagos (Mendoza: UNC, 1968), p. 153.

35 Rojas, María Elena Dixon. Vida jurídico-práctica contenida en los archivos notariales del Reino de Chile a fines del siglo XVIII. Breve estudio sobre la hipoteca (Santiago: Facultad de Derecho de la Universidad de Chile, tesis de grado, sin fecha), p. 1-2; Valenzuela, Carmen Cáceres. Vida jurídico-práctica contenida en los archivos notariales del Reino de Chile a fines del siglo XVIII. La Hipoteca (Santiago: Facultad de Derecho de la Universidad de Chile, tesis de grado, 1975), p. 1-3, 17, 24.

36 Préstamo hipotecario a Manuel Martínez Caballero y Bárbara León, Mendoza, 14 de noviembre de 1772. Protocolo de Escribano José Lagos (Mendoza: UNC, 1968), p. 79.

37 Préstamo hipotecario a Juan Manuel Sierra, Mendoza, 10 de julio de 1783. Protocolo de Escribano José Lagos (Mendoza: UNC, 1968), p. 60.

38 Préstamo hipotecario a Francisco Gallardo, Mendoza, 14 de agosto de 1787. Protocolo de Escribano José Lagos (Mendoza: UNC, 1968), p. 79. 
en 1775 se realizó una operación de "compra de unas carretas en \$200 y \$50 para habilitación de su tropa, hipotecando especialmente su tropa de carretas". ${ }^{39}$ En caso de incumplimiento del compromiso, las carretas podían salir a remate. Este fue lo que le sucedió a Juan Alonso de Carabajal, a quien le remataron seis carretas y 21 bueyes en $1774 .{ }^{40}$

El uso de la carreta como materia apta para la realización de una hipoteca, tiene un gran significado. Sobre todo porque se la elevaba a la altura de una propiedad raíz. La sociedad que otorgaba a la carreta la capacidad de ser puesta en garantía hipotecaria, estaba mostrando el elevado valor que le otorgaba a este medio de transporte. Se lo consideraba tan segura como la tierra. Evidentemente, el lugar que la carreta ocupó en la época colonial supera a muchos otros bienes y medios de producción. La carreta era un símbolo de seguridad, trabajo y prosperidad.

\section{Los troperos y el origen de la burguesía en el Cono Sur}

Afirmar la existencia de una burguesía (aunque sea de pequeñas dimensiones) en los confines de América Latina en el siglo XVIII puede parecer una provocación. ¿Es posible emplear esta categoría? En general, la literatura especializada sitúa el origen de la burguesía latinoamericana después de la Revolución de 1810, y con mayor claridad, entre mediados y fines del siglo XIX. De allí la necesidad de tratar con suma delicadeza el tema. Los aportes de Villalobos sirvieron para abrir el debate sobre este problema. En su libro Origen y ascenso de la burguesía chilena, el autor ha planteado la necesidad de poner en foco a esta clase social, especialmente por sus aportes desde el punto de vista de la creación de riqueza. El autor enfatiza:

qué habría sido Chile si no hubiese habido en el siglo XIX un dinámico grupo de mineros del cobre y de la plata en Atacama, pioneros del ferrocarril y la navegación a vapor, industriales arriesgados y banqueros activos. Ellos fueron los que juntaron los capitales, realizaron inversiones, exploraron el territorio, trajeron técnicos y ma-

39 Acta de obligación de pago de don José Rodríguez, Mendoza 10 de agosto de 1775. Protocolo de Escribano José Lagos (Mendoza: UNC, 1968), p. 80.

40 Acta de deuda de Juan Alonso de Carabajal, Mendoza, 17 de abril de 1774. Protocolo de Escribano José Lagos (Mendoza: UNC, 1968), p. 60. 
quinarias, y expusieron su fortuna en negocios audaces. Sin ellos habría que imaginar un país de tono rural y atrasado. ${ }^{41}$

Frente a tendencias historiográficas que observaron la burguesía para destacar las tensiones sociales y antagonismos con los trabajadores, Villalobos optó por rescatar el aporte de aquella clase en el proceso de creación de riqueza. Según este autor, en la construcción de la economía moderna de Chile, "fue la burguesía la gran clase dinámica". ${ }^{42}$ ¿Cuándo surgió la burguesía? Para Villalobos, esta clase emergió después de la Revolución de 1810. En la época colonial no existió la burguesía pues

la mejor designación para este sector es el de aristocracia terrateniente y comercial. Traspasado el umbral de la emancipación, todas las cosas comienzan a cambiar y al cabo de unas pocas décadas, es posible la decadencia de la aristocracia y el surgimiento de una burguesía con su nuevo estilo. ${ }^{43}$

En la época colonial no habría existido burguesía en la región. Para Villalobos, esta dinámica clase dirigente apareció con posterioridad, y respaldó la instauración de las instituciones propias del liberalismo político en Chile ¿Cuáles son las características que tiene la burguesía para Villalobos? Primero, destaca en la burguesía su voluntad de acumulación de capital; segundo, Villalobos asigna a la burguesía una tendencia frívola a la ostentación de riqueza y la vida lujosa, tanto en la forma de vestirse, la comida, la bebida y la arquitectura de sus viviendas; tercero, Villalobos asocia la burguesía con el comercio, las finanzas, la minería y el transporte; estas actividades distinguían a los burgueses de la antigua aristocracia chilena cuya base material se hallaba en la posesión de la tierra.

Frente a este marco teórico, el presente artículo se permite discrepar con Villalobos en dos aspectos centrales: por un lado, propone situar el origen de la burguesía casi un siglo y medio antes; segundo, plantea que uno de los pilares de esta burguesía fue el transporte terrestre de carretas y la actividad comercial llevada a cabo por los troperos.

Con respecto al surgimiento de la burguesía en la Argentina, los enfoques predominantes son bastante parecidos. Abelardo Ramos destaca la hegemonía de la burguesía comercial porteña,

41 Villalobos, Sergio. Origen y ascenso de la burguesía chilena (Santiago: Editorial Universitaria, 1987), p. 11-12.

42 Villalobos, Origen y ascenso, p. 19.

43 Villalobos, Origen y ascenso, p. 39. 
cuya estrategia fue, en la segunda mitad del siglo XIX, aliarse con la burguesía industrial británica e implementar el paradigma librecambista en la Argentina. Este fue el sentido de la Constitución Nacional de 1853 y la política posterior, sobre todo a partir de la presidencia de Bartolomé Mitre, al cual define como "el jefe de la burguesía comercial del puerto". ${ }^{44}$ De acuerdo a este autor, en general no existían burguesías en el interior del país.

Siguiendo a Max Weber, una de las notas propias de la burguesía es su ethos capitalista e innovador, realizado preferentemente en la industria, el comercio y las finanzas, en contraposición con los sectores más atrasados, feudales y señoriales, que fundaban su poder en la renta de la tierra y las minas. ${ }^{45}$ Los historiadores latinoamericanos han buscado la burguesía en el comercio marítimo, en los puertos de mar y junto a los ríos; pero todavía no consideraron que también podía hallarse en los puertos secos, en las bisagras articuladoras del transporte terrestre. Y que las flotas de carretas y recuas de mulas podían cumplir un papel equivalente a los barcos. Por las distancias que recorrían, esas carretas pueden ser homologadas a una flota de barcos; recordemos que en esos años, la acción de atravesar 1.000 ó $1.500 \mathrm{~km}$ de pampas para unir Mendoza con Buenos Aires o Santa Fe, se asociaba con el movimiento en el mar; debido a la ausencia de caminos, equipamiento, infraestructura ni seguridad, se hablaba en términos de "navegar por las pampas". ${ }^{46}$ Los troperos debían orientarse por las estrellas debido a la ausencia total de señales claras en las pampas, abierto mar verde en el cual debían desplazarse sin mayores referencias. Esta situación era claramente distinta del modelo dominante en América Latina, orientado hacia la producción primaria de exportación, ya de bienes agrícolas (café, algodón y azúcar), ya de metales (cobre, plata, oro). Y esta producción se realizaba sin acompañarla de flotas terrestres ni fluviales ni marítimas de capital local. Simplemente, los latifundistas latinoamericanos aguardaban que

44 Ramos, Jorge Abelardo. Revolución y contra revolución en la Argentina. II - Del patriciado a la oligarquía 1862-1904 (Buenos Aires: Plus Ultra, 6 edición, 1976), p. 43.

45 Weber, Max. Economía y Sociedad (México: Fondo de Cultura Económica, 1983), p 478.

46 "Todo el camino desde Buenos Aires a Mendoza, que se cuentan 300 leguas, es una llanura que parece a primera vista un mar; no se ve ni siquiera por milagro un árbol, ni se encuentra piedra alguna, no hay alojamiento a donde detenerse [...] se pasan ocho ríos y entonces se agregan a las carretas otros cuatro bueyes, porque por el gran peso de los carros se sepultan las ruedas en aquellos fangos o arenas de los ríos, que para sacarlas es necesario de los pobres bueyes y servidores". Fanelli, Antonio María. Relación del viaje desde Buenos Aires a Mendoza en 1699. Reproducido en: Lucero, Juan Draghi (ed.). Fuente americana de la Historia Argentina (Mendoza: Junta de Estudios Históricos, 1940), p. xxiv-xxv. 
los barcos de potencias europeas vinieran a comprar sus materias primas.

El ethos capitalista weberiano se notó también en los troperos, en su aporte a la dinamización de la economía desde el punto de vista financiero. Sus redes de contactos, su crédito y disponibilidad de capital los puso en situación de prestar dinero y agilizar las transacciones comerciales. Un buen ejemplo de troperosfinancistas puede ser el de don Mateo Delgado, a quien ya hemos visto como uno de los troperos principales de la región. Propietario de una importante flota de carretas, don Mateo construyó a la vez, una extensa red de relaciones comerciales. Y él mismo generaba, a veces, el crédito para que sus clientes y proveedores pudieran continuar y agilizar las actividades económicas. La lista de sus deudores, manifestada en su testamento, revela la amplitud de estas redes (ver Cuadro I).

\begin{tabular}{|c|c|c|c|}
\hline \multicolumn{4}{|c|}{$\begin{array}{c}\text { Cuadro I } \\
\begin{array}{c}\text { Créditos otorgados por el tropero Mateo Delgado vigentes } \\
\text { al redactar su testamento } \\
\text { Mendoza, } 1798\end{array}\end{array}$} \\
\hline Deudor & Perfil del deudor & Monto & Observaciones \\
\hline Tomás Carcaburu & \begin{tabular}{|l} 
Vecino de \\
Santiago de \\
Chile
\end{tabular} & $\$ 37.7$ & \\
\hline $\begin{array}{l}\text { El chileno carnicero } \\
\text { de San Vicente }\end{array}$ & $\begin{array}{l}\text { Natural de Chile, } \\
\text { vecino de } \\
\text { Mendoza }\end{array}$ & $\$ 70.4$ & $\begin{array}{l}15 \text { reses que le fié a } \\
\$ 4.4 \text { y una más a } \\
\$ 3 \text {. }\end{array}$ \\
\hline José Antonio Silva & & $\$ 190.0$ & $\begin{array}{l}\$ 30 \text { en plata y } 30 \\
\text { reses que le vendí a } \\
\$ 4 \text { cada una }\end{array}$ \\
\hline Antonio Silva & & $\$ 125.0$ & \\
\hline Luis García Beltrán & & $\$ 50.0$ & Le presté en plata \\
\hline Juan Pereyra & El portugués & $\$ 50.0$ & \\
\hline $\begin{array}{l}\text { José Clemente } \\
\text { Venegas }\end{array}$ & & $\$ 400.0$ & $\begin{array}{l}\text { Por unas mulas que } \\
\text { le he vendido }\end{array}$ \\
\hline Antonio Pereyra & & $\$ 340.0$ & $\begin{array}{l}\text { Una boyada y unas } \\
\text { vacas que le he } \\
\text { vendido }\end{array}$ \\
\hline $\begin{array}{l}\text { José Francisco } \\
\text { Amigorena }\end{array}$ & \begin{tabular}{|l|} 
Natural de \\
Buenos Aires, \\
comandante de \\
Armas de \\
Mendoza \\
\end{tabular} & $\$ 200.0$ & \\
\hline María Prudencia San & esposa de & $\$ 30.0$ & \\
\hline
\end{tabular}




\begin{tabular}{|c|c|c|c|}
\hline Jurjo & Amigorena & & \\
\hline $\begin{array}{l}\text { Francisco de Borja } \\
\text { Corvalán }\end{array}$ & Buenos Aires & $\$ 500.0$ & \\
\hline Total & & $\$ 1.993 .1$ & \\
\hline
\end{tabular}

La red de deudores de Mateo Delgado presenta varios datos de interés. En primer lugar se destaca la magnitud. Entre los once deudores le debían la suma de $\$ 1.993$ con 1 real, cifra considerable para la época. La cartera de clientes de don Mateo era muy variada geográfica, política y socialmente. Había portugueses, chilenos, porteños y cuyanos; algunos tenían residencia en Mendoza, otros en Santiago y Buenos Aires. Algunos estaban en la cúspide sociopolítica, como Amigorena, y don José Clemente Venegas; otros estaban más cerca de la base comercial, como el carnicero de San Vicente, de quien Delgado no recordaba el nombre. El crédito se otorgaba tanto en plata (García Beltrán y José Antonio Silva) como en especie (Venegas, Pereyra y el carnicero). En este sentido, don Mateo acostumbraba entregar bienes (sobre todo ganado) al fiado para agilizar sus propios negocios porque, además de tropero, trabajaba en el oficio del arreo y comercialización de ganado. Por otra parte, el documento revela que no era un rentista de dinero; en algunos casos, no sólo dejaba de cobrar los intereses sino que además, condonaba parte del capital prestado. En efecto, al referirse a la deuda que le debía Antonio Silva, don Mateo ordenó lo siguiente: "mando que no se le cobren más de $\$ 100$, pues los $\$ 25$ restantes se los perdono". ${ }^{47}$ La actividad financiera de los troperos estaba asociada a la dinamización de sus propios negocios como transportistas, comerciantes y productores.

Los troperos operaban en el mercado financiero no sólo como prestadores sino también como tomadores de dinero y crédito en especie. Un buen ejemplo fue el caso de don Antonio Lemos, el cual figuraba en la categoría de troperos frecuentes. Al redactar su testamento, Lemos reconoció tener deudas con numerosas personas; en algunos casos, sólo se menciona el acreedor: don Olegario Martínez; mi apoderado don Pedro García Díaz, don José Ferraris, don José Toribio Moyano y don Juan Gregorio Lemos; en otras oportunidades se especifica el monto adeudado: $\$ 568$ a don Juan Bautista Freytes; $\$ 220$ a don Benito Lucero; \$171.6 a don Norberto

47 Testamento de Mateo Delgado, Mendoza, 19 de julio de 1798. AHM, Protocolo de Escribanos no 136 fols. 148. 
Lucero; $\$ 50$ a don Melchor Jardel; $\$ 400$ a don Manuel Lemos; en total sus deudas con este grupo ascendían a $\$ 1.409 .48$ A ello habría que añadir un monto similar del grupo anterior, lo cual llevaría sus pasivos a $\$ 3.000$. Sobre la base de este crédito, don Antonio Lemos logró disponer de créditos de sus proveedores de bienes y servicios para hacer crecer su empresa de tropa de carretas. Un caso parecido fue el de Alejo Aldunate, también miembro del grupo de troperos frecuentes. En Río IV le debía a Juana Correa (\$25), a Antonio Arias, a don José Acosta y a un fulano (fierro por \$50). También tenía varias deudas en Buenos Aires, lugar donde, además, "tengo otorgada una escritura de imposición de \$300 de capital sobre mis bienes a censo redimible al 5\%".49 Además, en Mendoza le debía a varios viticultores, entre ellos \$168 a don Isidro Maza. Algunos créditos se otorgaban y pagaban en especie. Así por ejemplo, al mencionado Acosta le debía "10 bueyes, un caballo, una mula; y le tengo dado a cuenta de pago un barril de aguardiente de $\$ 15$, una petaca de moscatel en $\$ 13.1$ y 10 varas de lienzo fino a 5 reales". 50 En otros casos, don Alejo no era deudor sino acreedor: como ejemplo podemos mencionar los “\$120 que me tiene que entregar don Justo Arenas correspondiente al alquiler de cuatro carretadas de vasija que le alquilé, y \$425 del flete de cinco carretas para cargar frutas a $\$ 80$ cada una". ${ }^{51} \mathrm{El}$ sistema funcionaba con mayor agilidad porque el ganadero pampeano y el viticultor cuyano fiaban sus productos al tropero, mientras a su vez, éste les fiaba el transporte. Ante la escasez de dinero circulante, la red de confianza que construyeron los troperos permitió que se adelantaran bienes y servicios a crédito como mecanismo de agilizar los negocios.

En segundo lugar, Weber y Pernoud asocian la burguesía con las ciudades, en tanto que las tradicionales clases feudales tenían su base productiva en el campo. ${ }^{52}$ Sobre todo porque las ciudades operaban como encrucijadas, cruces de caminos comerciales en donde los mercaderes se encontraban, interactuaban y generaban una dinámica animación que terminaba por promover la circula-

48 Testamento de don Antonio Lemos, Mendoza, 24 de abril de 1810. AHM, Protocolo de Escribanos no 162 fols 40.

49 Testamento de Alejo Aldunate, Mendoza, 13 de octubre de 1797. AHM, Protocolo de Escribanos, $\mathrm{n}^{\circ} 133$ fols 153.

50 Testamento de Alejo Aldunate, Mendoza, 13 de octubre de 1797. AHM, Protocolo de Escribanos, $n^{\circ} 133$ fols 153 .

51 Testamento de Alejo Aldunate, Mendoza, 13 de octubre de 1797. AHM, Protocolo de Escribanos, no 133 fols 154-154 v.

52 Weber, Economía y Sociedad, p. 208. 
ción de las ideas, difundir las innovaciones tecnológicas, crear mercados y generar nuevas oportunidades de negocias; como resultado se lograba activar el comercio y la economía. En el caso de Mendoza, las características geográficas, sobre todo el clima seco (con precipitaciones del orden de los 200 milímetros anuales) y la economía de oasis, contribuyeron a generar una sociedad eminentemente citadina. Otro elemento que contribuyó a este fenómeno, además del clima, fue la posición estratégica de Mendoza en las rutas comerciales de la región. Por esta ciudad pasaban los principales caminos que vinculaban los mercados de la Cuenca del Plata con el Reino de Chile. Por tal motivo, centenares de troperos de carretas y arrieros de mulas entraban y salían constantemente de la ciudad, lo cual la dotaba de un movimiento y una dinámica muy particular. Además, cuando por causa de las nevadas, la cordillera quedaba cerrada, los arrieros debían permanecer en la ciudad días y hasta semanas, para luego continuar viaje hacia Santa Rosa, San Felipe, Santiago o Valparaíso. Ellos llenaban de vida las pulperías de la ciudad y la campaña, con sus relatos, sus noticias y sus sueños. Así lo detectó un agudo observador de la época, como Damián Hudson (1808-1877), el cual explicó el fenómeno en los siguientes términos: "En efecto, era notable para el viajero, para el hombre observador, el aspecto de animación y de cultura que presentaba la sociedad de Mendoza, el movimiento activo que ofrecía, a la vista, en su comercio interior y exterior". ${ }^{33}$ Una percepción muy parecida tuvo Juan Draghi Lucero, quien puso en foco la animación que generaban los arrieros y troperos en las ciudades cuyanas de los siglos XVIII y XIX. En una imagen literaria de aquella Mendoza tradicional, el autor describió un día de fiesta en los siguientes términos:

Los copetudos del pueblo, los ricos negociantes, los abasteros, los dueños de carretas, los viñateros y los militares bravos, batallaron por mostrar sus bien escondidos firuletes y no quedó baile antiguo que no fuera revivido, ni mudanza que no fuera entresacada del olvido. ¡Qué si aquello era una gloria de brillo y alegría! En la plaza hubieron bodegones bulliciosos. Mandó el brigadier general repartir los diez novillos carneados y varias carretadas con botijuelas de vino y fue de ver la churrasqueada con que se regalo el pobrerío. Ya los guitarreros hicieron trinar a sus instrumentos y se entabló el celado duelo entre arribanos y abajinos, a ver quiénes eran los dueños de los caudales de donosura en los zapateos y escobillados. Corría el

53 Hudson, Damián. Recuerdos históricos sobre la provincia de Cuyo, 1810-1851 (1 edición: 1898; 2 edición: 1931; 3 edición) (Mendoza: 1966), p. 314. 
vino en cantaritos y ensordecían los ¡huihas! de tanto pajuerano entonado. ${ }^{54}$

La escena se llena de animación, precisamente, porque Mendoza era el cruce de caminos, donde llegaban los arribanos (arrieros que llegaban de la Sierra, es decir, de Chile) y los abajinos (carreteros que venían de abajo, es decir, de las pampas rioplatenses). En otra parte, el autor plantea, en este mismo sitio, el espacio de encuentro entre los huasos chilenos y los gauchos pampeanos. Lucero describió la noticia del casamiento de una dama notable en los siguientes términos.

Un huaso, el más entonado de todos, le pegó este grito: 'ese mozo tan valiente, ¿es de sierra o es de pampa? ¡Queremos saberlo!' Avanzó el salvador y pidió silencio desde el balcón. '¡Soy del justo lugar en que nacen sierras y llanos!', dijo con ademanes medianeros. Se oyó un solo ‘¡Huija...!' de inmenso triunfo y alegría, y ya se vio que abajinos y arribanos se daban la mano en señal de amistad y apaciguamiento criollo. ‘¡Dentro de tres días es el casorio!...’ ¡Vaquillonas con cuero, vino, bailes y fuegos de artificio para puebleros, arribanos y abajinos!. 55

Puebleros cuyanos, arribanos chilenos y abajinos de las pampas, viticultoras, arrieros y troperos de carretas, fueron los actores sociales que se encontraban en plazas, mercados y pulperías para acrisolar una cultura dinámica y comercial en la región. Este proceso fue muy similar al que experimentó la burguesía europea en su etapa de constitución, tal como señala Pernoud: "Cuando en razón del mal tiempo los comerciantes no podían trasladarse, se establecían en las ciudades, de preferencia en aquellas que fueran centro de rutas, de modo que les resultara fácil reanudar su comercio en cuanto se los permitiera el tiempo o el deshielo". 56

La constante circulación de troperos y arrieros tuvo también efectos culturales. Su presencia en pulperías, mercados y fogones abrió el espacio a la circulación de ideas, despertaba curiosidad en los jóvenes y promovía, indirectamente, al movimiento y la acción. Draghi Lucero ha recreado este mundo en sus relatos, entre los cuales un ejemplo adecuado puede ser el siguiente:

El mocito trabó relación con gente de arria y los carreteros que llevaban el metal a los llanos. De noche iba al fogón de ellos y se embelesaba oyéndoles contar sus muchas peripecias. Oyó hablar de las

54 Lucero, Juan Draghi. Donde irás y no volverás. En: Las Mil y una noches argentinas (Buenos Aires: Colihue, 2001), p. 155.

55 Lucero, El media res, en: Las Mil y una noches argentinas, p. 204.

56 Pernoud, Régine. Los orígenes de la burguesía (Buenos Aires: Marisol, 1962), p. 21. 
penurias del marucho y supo del sufrido viajar de los arrieros por esas pampas infinitas. Tanto le dijeron del mundo y sus floridas novedades que, apenas cumplidos los dieciséis años, quiso salir a rodar tierras. 57

El fogón de los arrieros y troperos era el disparador, la chispa que excitaba la mente de los jóvenes y los impulsaba a viajar, a recorrer tierras lejanas y a buscar nuevas oportunidades para ganarse la vida. Vivir otras experiencias, conocer otras gentes, ampliar el horizonte mental. En otro cuento, el autor reiteraba el uso de este procedimiento como punto de partida:

El hijo soñaba con ser mocito y ganarse a hombre. De noche escuchaba, conteniendo el aliento, los cuentos de los arrieros y carreteros, y así se fue informando del mundo y sus desavenencias. La sed de rodar tierras le comenzó a trabajar el pecho y hasta forjaba aventuras de hombre resuelto y sin miedo. ${ }^{58}$

El relato del tropero construye un clima, una atmósfera cultural que atrae a los jóvenes, los excita y los empuja a salir de donde están. Actúa como una palanca generadora de movimiento y acción. Pone en marcha energías, vitaliza, estimula. Y el mozo se pone de pie, se suma al oficio del transporte, recorre sierras y pampas, descubre negocios, concibe ideas. Más tarde regresa a su pueblo natal, pero ya no es el mismo; llega cargado de inquietudes, propuestas e iniciativas. Sus familiares lo escuchaban con atención, y concebían nuevos planes. Se ponía en marcha un nuevo ethos sociocultural. En este contexto no es de extrañar que, en el seno de las familias de arrieros y troperos, se despertaran inquietudes de realizar viajes hacia lugares cada vez más lejanos. Un buen ejemplo puede ser el José Antonio Rojas (1732-1816). A través del matrimonio se unió con María Josefa Corvalán, quién lo vinculó directamente con una de relevante familia de arrieros y troperos. En efecto, su suegro, Juan de Corvalán, procurador de la ciudad de Mendoza, poseía ocho carretas con sus aperos. ${ }^{59}$ A ello podemos añadir al primo hermano de su esposa, don Nicolás Corvalán, el cual fue Regidor de Mendoza, viticultor, comerciante y tropero de carretas. ${ }^{60}$ Sus rutas lo llevaban a triangular entre Men-

57 Lucero, El cuerpo sin alma, en: Las Mil y una noches argentinas, p. 17.

58 Lucero, El Negro Triángulo, en: Las Mil y una noches argentinas, p. 51.

59 Ruiz, Jorge Comadrán. Las tres casas reinantes de Cuyo. Revista Chilena de Historia y Geografía, 126, 1958, p. 93; Villalobos, Sergio. El comercio y la crisis colonial (Santiago: Editorial Universitaria, 1990), p. 55.

60 Testamento de Nicolás Corvalán, Mendoza, 3 de julio de 1800. AHM, Protocolo de Escribanos $n^{\circ} 140$ fols. 54-57. 
doza, Buenos Aires y Santa Fe. ${ }^{61}$ En esta familia de arrieros y troperos, Rojas halló un entorno estimulante; viajó no sólo por la región, sino que llegó a Europa, donde permaneció largos años (1772-1778). Esta experiencia le facilitó las condiciones para acceder a los avances culturales de la época y luego difundirlos en su comunidad. Llevó a América la Enciclopedia y obras de Montesquieu, Bayle, Bufón, Rousseau y otros autores, incluyendo tratados de matemática, física, historia y geografía. Figuró entre los principales ilustrados de la región en esa época. Promovió diversas actividades económicas, entre ellas la minería. Sus vivencias le han dado un lugar en la literatura y la historia de los grandes viajeros de la época colonial. ${ }^{62}$

Las personas que alternaban en las pulperías, posadas y espacios sociales de la ciudad eran de muy distinta procedencia porque el gremio de los troperos y arrieros estaba formado por gentes especialmente aventurera y movediza. Entre los troperos permanentes que operaban desde y hacia Mendoza, muchos provenían de otros lugares. En efecto, sobre un total de 42 troperos registrados, los naturales de Mendoza eran 23 (54\%) y los forasteros 19 (45\%). Para visualizar con mayor claridad el perfil de los troperos que no eran naturales pero si avecindados en Mendoza, se ha elaborado el Cuadro II. De los troperos foráneos avecindados en Mendoza, la mitad eran europeos y la otra mitad americanos. Entre los europeos, la mayoría eran españoles peninsulares, pero había también un número relevante de portugueses. Los españoles llegaban tanto del norte de la península ibérica (Galicia) como del sur (Andalucía). Entre los americanos, había varios chilenos pero eran más los del virreinato del Río de la Plata. Se avecindaron en Mendoza tucumanos, cordobeses, puntanos y sanjuaninos.

\section{Extracción territorial de los troperos forasteros avecindados en Mendo-}

61 AHM, libros de Cargo y Data de 1794, 1797 y 1799.

62 Villalobos, ibid., p. 193; Fuentes, Jordi et al. Diccionario Histórico de Chile (Santiago: Editorial del Pacífico, 6 ed., 1977), p. 521-522; Sanhueza, Carlos. "De la periferia colonial al centro del Imperio. Viajeros chilenos en las cortes españolas durante el siglo XVIII y comienzos del siglo XIX" (Ponencia presentada en: IV Encuentro de Historia Colonial, Santiago, Universidad Andrés Bello, 23 al 25 de noviembre 2004). 


\begin{tabular}{|c|c|c|c|}
\hline \multicolumn{4}{|c|}{ Fines del siglo XVIII } \\
\hline Continente & Reino & $\begin{array}{l}\text { Provincia } \\
\text { ciudad }\end{array}$ & Nombre del tropero \\
\hline \multirow{10}{*}{$\begin{array}{l}\text { Europeos } \\
52,6 \%\end{array}$} & \multirow{6}{*}{$\begin{array}{l}\text { Españoles } \\
\text { peninsulares }\end{array}$} & Galicia & Felipe Calle \\
\hline & & Castilla & Tomás Carrasco \\
\hline & & Sin especificar & Fernando Jurado \\
\hline & & Santander & Esteban Rodríguez \\
\hline & & Andalucía & Manuel López \\
\hline & & Sin especificar & Juan Rodríguez \\
\hline & \multirow{4}{*}{ Portugueses } & Sin especificar & Félix Ferreira \\
\hline & & Sin especificar & Manuel Báez \\
\hline & & Sin especificar & Juan González \\
\hline & & Lisboa & $\begin{array}{l}\text { Francisco Javier } \\
\text { Da Silva }\end{array}$ \\
\hline \multirow{8}{*}{$\begin{array}{l}\text { Americanos } \\
47,3 \%\end{array}$} & \multirow{3}{*}{ Reino de Chile } & & Alejo Aldunate \\
\hline & & Santiago & Francisco Coria \\
\hline & & & José González \\
\hline & \multirow{5}{*}{$\begin{array}{l}\text { Virreinato del } \\
\text { Plata }\end{array}$} & Córdoba & Francisco Gallardo \\
\hline & & Tucumán & Mateo Delgado \\
\hline & & & Santiago Rojas \\
\hline & & San Luis & $\begin{array}{l}\text { Mariano de } \\
\text { la Concha }\end{array}$ \\
\hline & & San Juan & Vicente Ferrer \\
\hline
\end{tabular}

Gracias a su estratégica posición geográfica, Mendoza se convirtió en una encrucijada, un punto de encuentro entre comerciantes y transportistas de distintas regiones de la península ibérica y del Cono Sur. En las pulperías, posadas, plazas y mercados de la ciudad, se encontraban estos dinámicos y ambiciosos personajes, intercambiaban noticias, ideas y opiniones sobre los temas sociales, económicos, políticos y culturales de la época. Allí nacían amistades y sociedades entre partes sumamente diversas, marcadas por sus diferentes orígenes y experiencias. Allí se fue acrisolando un clima estimulante para los negocios; así se fue amasando lo que Weber llama "ethos capitalista". En este sentido es notable el paralelismo en el surgimiento de las primeras burguesías europeas con la de Mendoza, precisamente, por la localización geográfica y la característica de cruce de caminos.

Un tercer elemento importante para Weber es el apego de la burguesía a las relaciones de confianza y el orden jurídico, pues sus inversiones requieren de un plazo más largo que la agricultura anual para amortizarse. Además, la burguesía asume un papel activo en el permanente proceso de construcción del armazón jurídico. Para este autor, "las exigencias de la calculabilidad y confian- 
za en el funcionamiento del orden jurídico y la administración, una necesidad vital del capitalismo racional, condujo a la burguesía a concentrar su esfuerzo", entre otros objetivos, en "cooperar en las variaciones del orden jurídico". 63 En el caso estudiado, los troperos manifestaron claramente su preocupación por el poder político y el armazón jurídico. Ello se puso de manifiesto en las alianzas matrimoniales y redes sociales que se construyeron con tanto esmero en la época. Un buen ejemplo puede ser el matrimonio de María Josefa Corvalán, con José Perfecto Salas. Ella pertenecía a una relevante familia de troperos, viticultores y comerciantes de Mendoza, tal como se ha señalado. La red familiar de los Corvalán de Mendoza encontró un aliado estratégico en José Prefecto Salas: éste fue fiscal de la Real Audiencia de Chile durante tres lustros, principal consejero del virrey del Perú Manuel Amat y más tarde estrecho colaborador del primer virrey del Río de la Plata, Pedro de Cevallos. Los contactos con Salas se hicieron sentir sensiblemente en Cuyo: el fiscal ejerció una influencia tan fuerte que llegó a generar el recelo de sus adversarios, las intrigas y hasta la orden de la Corte de alejarse (él y su familia política) del Reino de Chile. ${ }^{64}$ Lo que aquí interesa es destacar que estos vínculos se tradujeron en medidas de gobierno que resultarían funcionales a los intereses de los transportistas y comerciantes cuyanos: desde sus espacios de poder, Salas promovió la fundación de pueblos y fuertes en San José de Corocorto (camino de Mendoza a Buenos Aires), San José de Jáchal (camino de San Juan a La Serena), y junto al río Diamante, en la frontera sur. Estas iniciativas contribuyeron en forma decisiva a incrementar la seguridad de los caminos frente a la amenaza de bandidos y malones indígenas. ${ }^{65}$ Salas impulsó también la construcción de la cárcel y edificios para el cabildo de Mendoza. Para financiar estar obras propuso "gravar cada mula y carreta que entraban a ella, aún cuando más no fuera en mínima cantidad".66 Salas actuaba sensibilizado por los problemas de arrieros y troperos; desde su encumbrada posición pública impulsaba medidas tendientes a la seguridad y el fortalecimiento de las instituciones políticas de la región, todo lo cual era funcional a la actividad industrial, transportista y comercial.

63 Weber, Economía y Sociedad, p. 238.

64 Ruiz, Jorge Comadrán. Las tres casas reinantes de Cuyo. Revista Chilena de Historia y Geografía, no 126, 1958, p. 77-127.

65 Donoso, Ricardo. El Dr. José Perfecto de Salas, fiscal de la Audiencia de Chile. Revista de Historia Americana y Argentina nº 3 y 4, Mendoza, 1958-1959, p. 33-54.

66 Ibid., p. 37. 
Los actores sociales y económicos de Mendoza tenían bastante sensibilidad para reaccionar cuando se presentaban problemas que pusieran en peligro sus negocios. Así se reflejó también en el conflicto suscitado con la guardia de Río IV en 1740, que culminó con el viaje de don Miguel de Arizmendi a Lima para negociar un nuevo orden jurídico con el Virrey del Perú; y en el incidente de las pulperías de Desaguadero, en 1805, que dio lugar a una reglamentación más rigurosa para el ramo de las pulperías. Los troperos percibían que, para la consolidación y el avance de sus negocios, era indispensable obtener mayor seguridad jurídica, remover obstáculos a la circulación de bienes y personas. En este sentido, los troperos basaban buena parte de su negocio en la capacidad de ser percibidos como actores confiables y fiables de la paz y el orden. Precisamente, esta confianza fue lo que condujo a las autoridades a poner en sus manos el traslado de armas y municiones de guerra en vísperas de las invasiones inglesas.

Los troperos de carretas tenían conciencia de sus intereses comunes, y llegaron a constituir una entidad que fue, tal vez, la primera organización gremial empresaria específica de la región: el Gremio de Carreteros. Esta entidad funcionó con motivo del pleito entre los transportistas y el empresario catalán Francisco Serra Canals, en torno a los derechos de pontazgo en el río Desaguadero. La historia de este pleito es bastante conocida, y puede verse en la bibliografía a la cual remitimos. Pero lo que aquí interesa es puntualizar la dinámica, la capacidad de organización, deliberación y acción de los carreteros que actuaron como corporación frente a otros intereses privados o bien, contra el Cabildo de Mendoza. ${ }^{67}$

En cuarto lugar, Weber establece que una característica importante de la burguesía es su perfil de "clase lucrativa", la cual se caracteriza por "las probabilidades de la valoración de los bienes y servicios en el mercado determinan de un modo primario la situación de clase". En este sentido, tal como examina María Celia Duek, conviene distinguir burguesía, en cuanto vanguardia del proceso económico, de las clases rentistas. ${ }^{68}$ La burguesía es diferente de la "clase rentista", en la cual "las diferencias de propiedad determinan de un modo primario la situación de clase". ${ }^{69}$ En Amé-

67 Martínez, Pedro Santos. Historia Económica de Mendoza durante el virreinato, 1776-1810 (1 edición: Mendoza, 1961; 2 edición) (Buenos Aires: Ciudad Argentina, 2000), p. 205-234.

68 Duek, María Celia. Las teorías de las clases sociales: lectura, sistematización y análisis comparado (Mendoza: Universidad Nacional de Cuyo, Tesis de Maestría, 2001), p. 111-117.

69 Weber, Economía y Sociedad, p. 243. 
rica Latina predominaban las clases rentistas de tierras, minas y dinero. En las grandes plantaciones de Cuba, Brasil o Colombia, era muy difícil modificar esta situación o llegar a las clases altas para aquellos que, originalmente, carecían de estas grandes propiedades. En cambio, en Mendoza, como la tierra carecía de valor (por ser improductiva salvo con fuertes inversiones en obras de riego y con producción intensiva), las condiciones no eran propicias para el surgimiento de una clase rentista. Por el contrario, la base de la riqueza era el trabajo intensivo en el cultivo de la viña, la elaboración del vino, el transporte en carretas o mulas y el comercio con los mercados de Chile, Paraguay y el Río de la Plata. A diferencia de las clases rentistas, los troperos corrían riesgos, es decir, realizaban lo que Max Weber plantea como "ethos capitalista". En sus viajes podían perder sus bienes y hasta la vida, tal como ocurrió en varias oportunidades, ya en Córdoba, ya en el Desaguadero. No obstante ello, los carreteros enfrentaban el peligro y corrían los riesgos.

La burguesía de Mendoza, como sucede habitualmente, no se encuadra en el tipo ideal de Weber. Así por ejemplo, la burguesía contemporánea se caracteriza por tener relaciones económicas con trabajadores libres y asalariados. Pero los arrieros y troperos tenían muy pocos esclavos; y por lo general, los que tenían, estaban destinados a otras actividades económicas.

Dejando de lado las teorias weberianas y pasando a las marxistas, también surgen luces para interpretar el papel de las carretas y su tráfico en la formación de la burguesía regional. Sobre todo porque el marxismo pone énfasis en el carácter de apropiación del trabajo de las clases subordinadas en el surgimiento de las burguesías. Y esto fue exactamente lo que sucedió con los troperos de carretas que se beneficiaron del tráfico de esclavos como mecanismo para enriquecerse y acumular capital. El ascenso de esta emergente y dinámica clase social se hizo, en buena medida, sobre la base del dolor, las lágrimas y la sangre de decenas de miles de esclavos de origen africano que se apretujaban a bordo de las carretas en la interminable travesía de las pampas.

En el transporte de "piezas" humanas, yerba mate, vino y otras cargas, las carretas dinamizaron la economía regional. Permitieron el desarrollo del transporte, el comercio y las finanzas y la industria vitivinícola en la región. Se puso en marcha un modelo de actividad económica de tipo lucrativo y el surgimiento de una burguesía en el Cono Sur. 